\title{
TILO MANURUNG: \\ REPRESENTASI CERITA MASYARAKAT SUKU BUOL SULAWESI TENGAH PADA KOMPOSISI MUSIK ETNIS SIRITANO SINDA
}

\author{
Ananda Dwi Septavauzan \\ Program Studi S-1 ISI Yogyakarta \\ Email : nandad885@gmail.com
}

\begin{abstract}
Abstrak
Komposisi Siritano Sinda merupakan bentuk representasi dari sebuah mitos yang ada di Sulawesi Tengah. Siritano Sinda diartikan sebagai cerita tentang cinta dalam pejalanan hidup Lilimbuta dan Lilimbuto yang disebut Tilo Manurung dari proses lahirnya melalui bambu kuning sebagai perantaranya, mendapatkan tindak rasis dari masyarakat hingga mereka malarikan diri dan berikrar cinta. Berdasarkan pengamatan pengkarya, kisah tentang Tilo Manurung sangat penting untuk dipublikasikan sebagai pengetahuan budaya, serta menjadi contoh kepada khalayak betapa pentingnya untuk mempertahankan identitas dari sebuah budaya yang sangat minim diketahui oleh para generasi penerus. Dalam hal ini, gagasan utama dalam karya musik etnis yang berjudul Siritano Sinda adalah bagaimana mewujudkan ide atau gagasan yang mengacu pada kisah perjalanan cinta Lilimbuta dan Lilimbuto ke dalam bentuk musik etnis.

Metode yang digunakan dalam proses penciptaan musik etnis yang berjudul Siritano Sinda mengacu pada teori Alma M. Hawkins. Teori ini berisi tentang proses penciptaan yaitu Eksplorasi, Improvisasi, dan Pembentukan.

Penyajian komposisi Siritano Sinda merupakan perpaduan dari instrumen etnis Nusantara, instrumen barat dan vokal yang terinspirasi dari sebuah grup musik yang bernama wagakki. Gambus Jepeng merupakan pola permainan utama dari karya ini. Selain itu, pola permainan yang khas dari suku Buol adalah pendukung terciptanya komposisi musik etnis yang berjudul Siritano Sinda. Secara garis besar nuansa dalam karya ini merupakan representasi dari peristiwa yang terjadi pada Lilimbuta dan Lilimbuto yang terdiri dari tiga bagian yaitu, kelahiran, kehidupan, dan pertemuan.
\end{abstract}

Kata Kunci : Siritano Sinda, Tilo Manurung, Wagakki

\begin{abstract}
The composition of Siritano Sinda is a form of representation of a myth that exists in Central Sulawesi. Siritano Sinda is interpreted as a story about love in the life journey of Lilimbuta and Lilimbuto called Tilo Manurung from its birth process through yellow bamboo as its intermediary, getting racist acts from the community until they ran away and vowed love. Based on the observations of the authors, the story of Tilo Manurung is very important to be published as cultural knowledge, as well as being an example to the public how important it is to maintain the identity of a culture that is very little known by future generations. In this case, the main idea in an ethnic music work entitled Siritano Sinda is how to realize an idea or idea that refers to the love story of Lilimbuta and Lilimbuto in the form of ethnic music.

The method used in the process of creating ethnic music called Siritano Sinda refers to the theory of Alma M. Hawkins. This theory contains the process of creation, namely Exploration, Improvisation, and Formation.

The presentation of Siritano Sinda's composition is a fusion of ethnic Nusantara instruments, western instruments and vocals inspired by a music group called wagakki. Gambus Jepeng is the main play pattern of this work. In addition, the distinctive playing patterns of the Buol tribe are supporters of the creation of ethnic musical compositions entitled Siritano Sinda. Broadly speaking the nuances in this work are representations of events that occurred at Lilimbuta and Lilimbuto which consisted of three parts namely, birth, life, and meeting.
\end{abstract}

Keywords : Siritano Sinda, Tilo Manurung, Wagakki 


\section{A. Latar Belakang}

Siritano Sinda merupakan bahasa dari sari suku Buol yang dalam bahasa Indonesia berarti "Cerita tentang Cinta", Siritano dalam bahasa Indonesia berarti "sebuah cerita", sedangkan Sinda berarti "Cinta". Siritano Sinda juga merupakan bahasa dari suku Buol. Karya yang berjudul Siritano Sinda terinspirasi dari kisah Tilo Manurung yang merupakan mitos dari provinsi Sulawesi Tengah Kabupaten Buol. Judul ini dipilih karena ingin menceritakan sebuah kisah cinta dari Tilo Manurung yang merupakan sepasang kekasih. Tilo Manurung dalam bahasa Indonesia adalah sepasang manusia bambu atau sepasang manusia yang keluar (lahir) dari bambu. Sebagian masyarakat percaya bahwa Tilo Manurung adalah manusia ke-3 yang diturunkan ke bumi setelah keturunan Nabi Adam As, dan juga dipercaya bahwa mereka diturunkan (lahir dari bambu) setelah Bahtera Nabi Nuh As mengililingi laut Sulawesi sebanyak 3 kali sehingga buih dari bahtera Nabi Nuh As membentuk pulau Sulawesi ketika surutnya banjir besar pada masa itu. Tilo Manurung sendiri keluar dari bambu kuning yang dipercayai oleh sebagian masyarakat Sulawesi Tengah adalah tumbuhan yang diyakini sebagai pagar dan berperan untuk membatasi antara alam gaib dan alam nyata. Bambu kuning juga digunakan untuk prosesi atau upacaraupacara adat di Kabupaten Buol. Tilo
Manurung juga dikenal sebagai Lilimbuta agu Lilimbuto yang merupakan nama dari seorang laki-laki dan perempuan yang lahir dari bambu.

Pada zaman dahulu kala, saat Tilo Manurung keluar dari bambu mereka berdua jatuh cinta satu sama lain, akan tetapi masyarakat keturunan ke-2 yang bernama suku Botu Moitom (batu hitam) yang sudah berada sebelum Tilo Manurung tidak merestui jika mereka menjalin suatu hubungan. Masyarakat menganggap bahwa, apabila Tilo Manurung dipersatukan cinta mereka, maka akan mendatangkan musibah besar, alasannya karena mereka adalah jelmaan manusia yang keluar dari bambu kuning dan dipercaya sebagai pembatas antara alam gaib dan alam nyata. Karena alasan dari masyarakat itu, Lilimbuta sempat diusir oleh keturunan Botu Moitom ke daerah yang bernama Pinamula. Pada saat itu Lilimbuta membuat suatu perjanjian dengan Lilimbuto bahwa suatu hari nanti jika Tuhan berkehendak maka mereka akan bertemu kembali. Setelah bertahun-tahun, secara tidak sengaja mereka bertemu di sebuah gunung yang bernama gunung Pogogul yang dipercaya adalah tempat kelahiran Tilo Manurung dan dianggap keramat oleh masyarakat sekitar. Setelah itu mereka berdua melangsungkan pernikahan tanpa adanya saksi, mereka hanya memohon restu kepada gunung 
Pogogul (Pogoguyo) dan Sang Maha Kuasa. Setelah itu mereka hidup bersama dan mengurung diri di tanah Pogogul (A. Rahman Samad, tt : 8).

Alasan terciptanya karya yang berjudul Siritano Sinda karena pengkarya ingin menghadirkan cerita Tilo Manurung ke dalam bentuk pertunjukan komposisi musik etnis, serta pengkarya berharap agar makna dari cerita Tilo Manurung dapat tersampaikan kepada khalayak, di samping ingin mengajak masyarakat suku Buol untuk tidak melupakan sejarah dari nenek moyang yang merupakan identitas dari masyarakat suku Buol itu sendiri. Makna yang terkandung dalam cerita Tilo Manurung adalah sebagai makhluk Tuhan yang paling sempurna jangan hanya menilai orang dari sisi luarnya saja, akan tetapi juga harus melihat dari sisi dalamnya. Cinta adalah sebuah perasaan yang diberikan oleh Tuhan pada sepasang manusia untuk saling mencintai, saling memiliki, saling mengisi, dan saling pengertian. Setiap manusia yang sabar dan tawaqal pasti akan mendapatkan hasil yang baik pada akhirnya. Jika semua terlaksana sesuai dengan harapan yang dipikirkan pengkarya, maka terciptalah sebuah harmoni sehingga membuat sebagian manusia tidak perlu lagi mengalami hal yang terjadi pada kisah Tilo Manurung.

Cerita ini pernah dijadikan sumber dalam karya Tilo Manurung yang sebelumnya disajikan pada ujian penciptaan musik etnis. Karya yang berdurasi 15 menit tersebut memiliki pokok pembahasan yang sama dengan karya yang disajikan dalam tugas akhir penciptaan musik etnis ini, akan tetapi memiliki perbedaan dalam bentuk penyajian, instrumentasi, pengolahan melodi, serta lebih berfokus pada penokohan Lilimbuta dan Lilimbuto yang di visualisasikan melalui instrumen etnis Buol dan gerak tari.

\section{Alih Wahana}

Damono (2017) menjelaskan bahwa alih wahana merupakan sebuah kontruksi mengubah bentuk kesenian menjadi kesenian lain, hal ini didasarkan bahwa sifat kesenian adalah dinamis dan pandangan emic yang dimiliki oleh masyarakat menyebabkan intepretasi yang berbeda pula terhadap sebuah obyek yang diamati, di dengar. Bukan hanya sekedar mengalihkan saja, tetapi Damono juga menambahkan bahwa konsep komunikasi sebagai sebuah tanda yang harus diintepretasi oleh intepretant memberikan sebuah kebebasan penilaian tetapi dengan standar wilayah kultural masing-masing masyarakat, oleh karena itu Damono menggambarkan dengan suara ayam berkokok yang di intepretasi dengan gaya yang berbeda-beda. 


\section{B. Metode Penelitian Penciptaan}

Proses penciptaan dalam komposisi musik metode sangat penting untuk pengkarya pada proses penciptaan. Dalam hal ini, pengkarya menggunakan teori yang dikemukakan oleh Alma M. Hawkins (1990: 26). Mencipta Lewat Tari Yogyakarta: Institut Seni Indonesia tentang metode proses penciptaan yang menurutnya metode dalam proses penciptaan diklasifikasikan menjadi tiga bagian utama yaitu eksplorasi, improvisasi, serta pembentukan selain itu, pengkarya juga menambahkan satu metode yang diterapkan pada proses penciptaan komposisi musik etnis yang berjudul Siritano Sinda, yaitu proses inspirasi (pemunculan ide) pada bagian awal berdasarkan dari pedoman penulisan tugas akhir penciptaan musik etnis.

Karya yang disajikan oleh pengkarya menggunakan vokal, gambus dan kulintang sebagai media utama dalam komposisi yang ditawarkan, dipadukan dengan beberapa instrumentasi seperti hawaiian, kecapi sunda, sasando flute, biola, cello, bass, cymbal, rebana, dan multiple sebagai pendukung untuk membangun suasana yang diinginkan oleh pengkarya. Pada tahap awal, pengkarya menentukan tema komposisi musik yang akan disajikan. Setelah itu, menentukan bagian-bagian yang diperlukan dengan maksud untuk memperjelas alur dari musik tersebut.
Proses inspirasi (pemunculan ide), pengkarya menggunakan gambus dan kulintang untuk menentukan melodimelodi pokok sebagai benang merah terciptanya komposisi musik melalui tahap perenungan (imajinasi). Alasan pengkarya menggunakan kedua instrumen tersebut, karena perwujudan untuk penokohkan sosok Tilo Manurung terdapat pada instrumen gambus dan kulintang, serta merupakan alat musik tradisi dari daerah Buol yang diacu dari buku yang di tulis oleh Supardi Djoko Damono (Jakarta: Gramedia Pustaka Utama, 2018: 9) Alih Wahana.

Eksplorasi dilakukan oleh pengkarya dengan tujuan mengetahui, menemukan dan mengidentifikasi musik agar sesuai dengan tema dari komposisi musik Siritano Sinda yang diharapkan oleh pengkarya. Setelah ditentukannya melodi, pengkarya masuk pada tahap improvisasi. Melodi dengan menggunakan instrumen pendukung yang telah ditentukan, berangkat dari dua hal yaitu pola tradisi dan pola yang diciptakan sendiri melalui tahap inspirasi dan kreatifitas pengkarya, serta pengembangan pola dari instrumen utama yaitu gambus dan kulintang.

Proses pembentukan komposisi musik, pengkarya berangkat dari pola yang telah tercipta melalui proses kreatifitas (rangsang awal, inspirasi, eksplorasi, dan improvisasi). Di tahap panyajian pengkarya menggabungkan media utama yaitu vokal, 
gambus, dan kulintang dengan instrumen pendukung yaitu kecapi sunda, sasando, flute, biola, cello, bass, cymbal, rebana, dan bedug untuk mendukung suasana yang akan disajikan dengan cara menempatkan instrumen pendukung pada bagian-bagian tertentu sehingga tercipta suasana yang diharapkan oleh pengkarya. Dalam hal ini, pengkarya membagi komposisi musik Siritano Sinda menjadi tiga bagian yaitu awal (kalahiran), tengah (kehidupan), dan akhir (pertemuan).

\section{Hasil dan Pembahasan}

masyarakat itu sendiri. Permasalahan tersebut memacu pengkarya karena di daerah pengkarya sudah sangat sering ditemukan bahwa para generasi muda pada saat ini tidak mengetahui identitas kebudayaan mereka sendiri serta tidak banyak yang tahu soal asal-usul nenek moyang mereka pada zaman dahulu. Hal ini yang menjadi rangsangan pengkarya mendapatkan ide untuk membuat komposisi musik etnis yang berjudul Siritano Sinda. Terlepas dari itu, karya Siritano Sinda itu sendiri merupakan sebuah cerita yang terinspirasi oleh mitos dari daerah Buol. Alasan pengkarya memberi judul tersebut pada karya ini

\section{Ide Penciptaan}

Ide merupakan gagasan atau rancangan yang tersusun dalam pikiran serta berperan sebagai rangsangan untuk membantu pengkarya menuangkan konsep ke dalam bentuk karya atau tulisan. Seiring berkembangnya zaman maka kebudayaan dalam suatu masyarakat perlahan akan mengikutinya. Hal ini berdampak pada kebudayaan di suatu kelompok masyarakat yang secara perlahan mulai dilupakan oleh generasi masa kini dan masa yang akan datang, serta akan mempengaruhi identitas

karena ingin menyampaikan bahwa segala kehidupan yang ada di muka bumi ini harus dijalani dengan penuh cinta, dengan cinta kita bisa berbagi satu sama lain.

Karya ini mempunyai tiga bagian pokok musikal untuk mewakili suasana yang terdiri dari bagian awal (kelahiran), tengah (kehidupan), dan akhir (pertemuan). Oleh sebab itu, setiap bagian yang ada dalam karya ini terdapat rangkaian alur untuk mendespripsikan peristiwa yeng terjadi di kisah Tilo Manurung ke dalam bentuk komposisi musik. Bagian-bagian dalam karya ini dapat dilihat pada skema yang memiliki susunan sebagai berikut. 

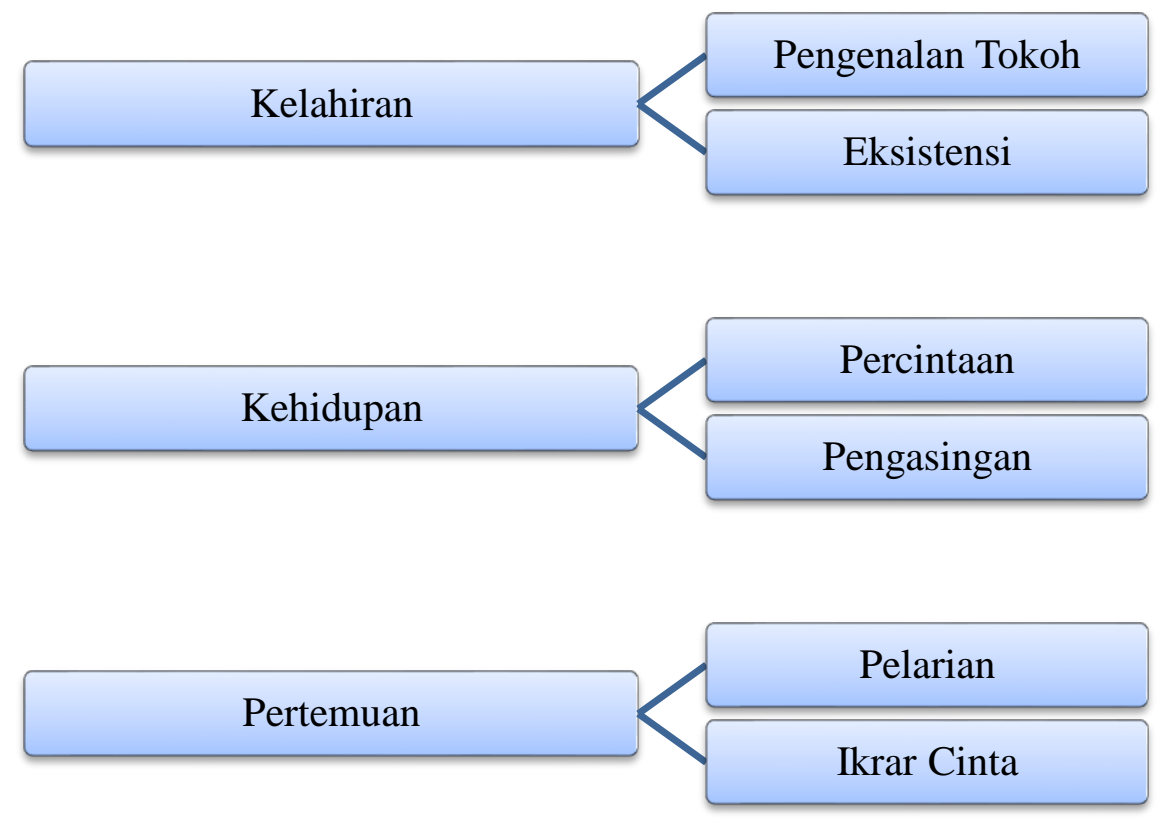

Gambar 1. Skema alur karya Siritano Sinda

Skema di atas menjadi acuan pengkarya dalam proses penciptaan komposisi musik etnis yang berjudul Siritano Sinda. Skema tersebut juga dapat merangsang pengkarya untuk dapat menentukan nuansa pada alur komposisi ini, agar mendapatkan melodi yang sesuai dengan konsep komposisi yang diinginkan. Pengkarya menggunakan instrumen gambus dan kulintang (kakula) sebagai media pengolahan suatu melodi. Pengkarya menggunakan gambus dan kulintang sebagai media utama karena kedua instrumen tersebut merupakan alat musik tradisi yang berasal dari daerah pengkarya yaitu daerah pesisir Sulawesi Tengah Kabupaten Buol selain itu, penerapan melodi pada instrumen modern juga digunakan dalam karya ini berdasarkan hasil pengolahan melodi yang sudah dibuat melalui kedua instrumen utama tersebut dengan cara mengunakan teknik imitasi.

\section{Tema Penciptaan}

Tema menurut KBBI adalah pokok pikiran, gagasan utama, atau ide pokok yang dipikirkan oleh pengkarya. Secara umum tema juga bisa diartikan sebagai pondasi utama dalam sebuah karya, hal ini yang membuat pengkarya dapat menyusun tema musikal dalam karya yang berjudul Siritano Sinda. Tema musikal yang dimaksud adalah suasana yang terkandung dalam kisah Tilo Manurung yang diaplikasikan ke dalam bentuk sebuah musik, serta pesan yang terkandung dalam kisah tersebut. Secara garis besar bentuk 
lagu pada komposisi musik etnis ini terinspirasi dari pola permainan Gambus Jepeng, akan tetapi pola permainan gambus dalam karya ini telah melewati tahap improvisasi dan ditambahkan teknik augmentasi sehingga bentuk lagu dalam karya Siritano Sinda memiliki originalitas. Bentuk lagu yang menjadi tema dasar penciptaan musik etnis Siritano Sinda adalah sebagai berikut.

Gambus :

$\ldots 3 \| 6 \ldots|\ldots 7| 5 \ldots|\ldots 3 \overline{23}|$ $4 \ldots 6|5 \ldots 6| 3 \ldots|\ldots 3|$

Melodi di atas diciptakan berdasarkan proses imajinasi dan pengolahan melodi dari pola permainan Gambus Jepeng, serta menggunakan buku yang ditulis Karl Edmund Prier SJ (1996: 27), Ilmu Bentuk Musik, Yogyakarta: Pusat Musik Liturgi. Tema Musik pada karya ini juga mengacu pada peristiwa kehidupan yang terjadi pada Lilimbuta dan Lilimbuto, dalam hal ini nuansa Melayu yang terkandung pada karya Siritano Sinda dikembangkan dengan menggunakan instrumen-instrumen pendukung serta teknik-teknik dasar pengelohan komposisi musik.

\section{Bentuk (Form)}

Bentuk merupakan aspek yang tidak bisa lepas proses penciptaan. Di dalam bentuk musikal terdapat sekumpulan elemen-elemen yang meliputi melodi, ritme, serta harmoni. Berdasarkan pernyataan tersebut, karya yang berjudul Siritano Sinda memiliki bentuk musikal yang tidak bisa lepas dari seluruh elemenelemen yang telah disebutkan. Bentuk dalam karya musik etnis ini berbentuk campuran vokal instrumental yang terinspirasi dari sebuah grup musik yang bernama Wagakki. Grup Wagakki merupakan sebuah grup musik asal Negara Jepang yang menggabungkan dua elemen musik yaitu tradisional Jepang dan modern. Hal ini menginspirasi pengkarya untuk menggabungkan dua elemen musik yaitu instrumen tradisional Nusantara dan instrumen Barat. Pola permainan instrumen dalam karya ini merupakan pengolahan motif pada permainan Gambus Jepeng yang merupakan pola permainan dari daerah Buol.

Penyusunan melodi, ritme, serta harmoni ditentukan oleh hasil wawancara serta pemahaman pengkarya tentang alur peristiwa terhadap kisah Tilo Manurung. Berkaitan dengan hal ini, Winnardo Saragih (2008 : 8). Misi Musik, Yogyakarta: ANDI, mengungkapkan bahwa musik merupakan media untuk menyampaikan sesuatu hal. Dalam hal ini pengkarya merepresentasikan 
kisah yang terinspirasi dari Tilo Manurung ke dalam bentuk musik sehingga terciptalah karya yang berjudul Siritano Sinda.

Dari hasil wawancara dengan tokoh Adat Buol terdapat sebuah makna yang terkandung dalam kisah dari Tilo Manurung yaitu keteguhan serta kesabaran seseorang. Demi mempertahankan cintanya pasti akan dimudahkan jalannya oleh Tuhan yang Maha Esa. Karya ini menggunakan instrumen tradisional Nusantara yaitu kecapi Sunda yang digunakan dengan tangga nada diatonis, sasando yang merupakan instrumen dari daerah NTT, hawaiian yang berasal dari daerah Ambon, bedug, serta gambus, kulintang dan rebana yang berasal dari daerah Buol. Instrumen tersebut digunakan sebagai benang merah yang dipadukan dengan beberapa instrumen barat yaitu flute, biola, cello, bass, xylophone, dan multiple demi menciptakan nuansa yang diharapkan pada komposisi musik etnis yang berjudul Siritano Sinda.

\section{Struktur Komposisi}

Struktur komposisi pada karya yang berjudul Siritano Sinda ini terdapat tiga bagian utama dari awal hingga akhir, yang tertuju pada perjalanan atau kisah kehidupan yang telah dilalui oleh Lilimbuta dan Lilimbuto. Bagian-bagian pada struktur komposisi karya ini terdiri dari peristiwa kelahiran Tilo Manurung (pengenalan dan eksistensi tokoh), kehidupan (percintaan dan pengasingan), dan pertemuan (pelarian dan ikrar cinta). Bagian Awal (kelahiran)

Bagian ini berisi pola permainan flute yang merupakan pengantar sebagai awal dimulainya kisah dari Tilo Manurung dengan memainkan musik tema dari keseluruhan karya ini dan dikembangkan dengan menggunakan teknik improvisasi dan repetisi, dilanjutkan oleh vokalis utama sebagai intro dan teknik canon oleh seluruh pemain, vokal tersebut dinyanyikan sebanyak dua kali pengulangan dengan menggunakan teknik khas Melayu suku Buol berupa Unugon. Berikut adalah bentuk notisanya.

\section{a. Bagian Awal (kelahiran) \\ Bagian ini berisi pola permainan flute} yang merupakan pengantar sebagai awal dimulainya kisah dari Tilo Manurung dengan memainkan musik tema dari keseluruhan karya ini dan dikembangkan dengan menggunakan teknik improvisasi dan repetisi, dilanjutkan oleh vokalis utama sebagai intro dan teknik canon oleh seluruh pemain, vokal tersebut dinyanyikan sebanyak dua kali pengulangan dengan menggunakan teknik khas Melayu suku Buol berupa Unugon. Berikut adalah bentuk notisanya. 
Tangga nada Minor diatonis $\mathrm{La}=\mathrm{G}$

4/4

Adagio

Flute $: \ldots 3\|6 \ldots|\ldots 7| 5 \ldots|\ldots 3 \overline{23}| 4 \ldots 6|5 \ldots 6| 3 \ldots \mid \ldots 3\|$

*flute dimainkan dengan menggunakan teknik improvisasi

Cello : $\| 6 . . .|\ldots$.

$\begin{array}{lllllllll}\text { Vokal utama } & : 3 & 4 & 6 & 5 & 4 & 5 & 4 & 3\end{array}$

Tia - siri - ta Ti - lo Ma - nu-rung

(ini cerita Tilo manurung)

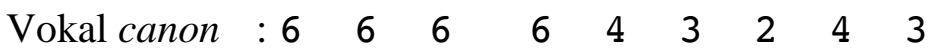

$K i$ - sah ten - tang cin - ta me - re - ka

Nuansa musik dan pola permainan yang telah dipaparkan di atas merupakan salah satu perwujudan dari peristiwa mulai dari lahirnya kedua sosok Tilo Manurung sampai peristiwa di mana kedua manusia tersebut mempertanyakan eksistensi mereka selain itu, nuansa yang dibangun pada bagian komposisi musik ini merupakan hasil dari proses eksplorasi tema besar sehingga terciptalah beberapa pola yang dijadikan sebagai benang merah untuk bagian awal Siritano Sinda.

b. Bagian tengah (kehidupan)

Bagian ini merupakan representasi dari peristiwa di mana sepasang manusia yang lahir dari bambu kuning tersebut melangsungkan kehidupan dalam kelompok masyarakat yang telah menampung mereka berdua. Dalam bagian ini pengkarya mencoba menuangkan peristiwa saat Lilimbuta dan Lilimbuto bertemu untuk pertama kalinya dan jatuh cinta satu sama lain berkat kelompok masyarakat yang menolong dan sudah hidup sebelum mereka berdua dilahirkan. Musik pada bagian ini, sekaligus merepresentasikan konflik yang terjadi antara sepasang Tilo Manurung dan kelompok masyarakat yang menampung mereka berdua. Konflik yang dimaksudkan di sini ialah terungkapnya identitas dari sepasang manusia yang merupakan jelmaan dari bambu kuning dan pengasingan terhadap Lilimbuta (laki-laki), karena masyarakat percaya ketika kedua manusia yang disebut Tilo Manurung manjalin cinta maka bencana besar akan terjadi seperti 
halnya peristiwa kelahiran dari kedua manusia tersebut. Nuansa yang dihadirkan pada bagian ini meliputi kebahagiaan dan kesedihan. Dengan menggunakan teknik repetisi sebagai dasar pengolahan motif dan tanya jawab pada instrumen tradisi,

Tangga nada Minor $\mathrm{La}=\mathrm{G}$

4/4

Moderato kemudian dibalut dengan dengan teknik filler oleh intrumen barat dapat membantu pengkarya merepresentasikan dari peristiwa yang ingin disampaikan pada bagian ini. Berikut merupakan bentuk susunan notasinya.

\section{A}

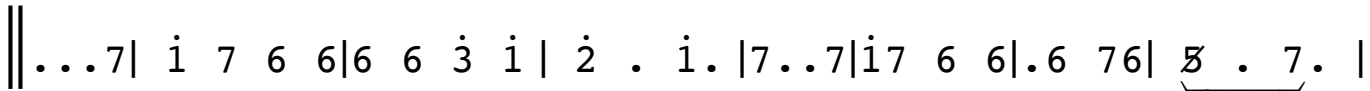

Ki-to motumumu-yo kodo- ku - ni -mu kodoto-kolyo ku-ana-ku

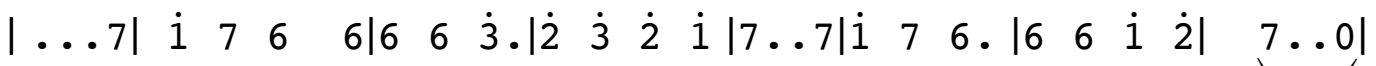

po-gi-leengu a-ku-ni-mu ko-andu-kanum potinggai ko-po-noman-do

|. i $75|\underbrace{6 \overline{54}} \ldots| 4.6$ i $|\underbrace{\overline{2} \dot{1}} 7 \ldots| \underbrace{5 \ldots 7}|\underbrace{7 \ldots \mid} 7 \ldots| 7 \ldots 0 \mid$

a-ku dii-la mo-ba-tal-yo jan - ji

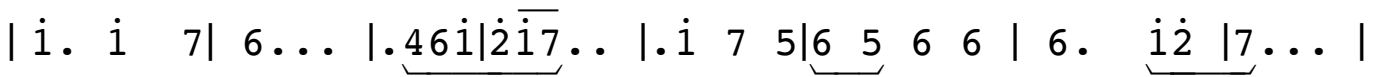

ber-sa-bar-lah hoo ki-to ta-taa-po po-ting-gai

$|\underbrace{i . i 7}| 6 \ldots|.6 \dot{3} \quad i| \underbrace{2} \overline{i 7} \ldots|. \dot{i} 75| 6 \quad 5 \underbrace{6 i}|\dot{2} .7.| \underbrace{6.0}||$ ja - ngan motombo-yu tan-da-ni-o kobvu kokol-yab

Arti dari lagu di atas:

Kita hidup untuk saling memiliki

Kumohon dirimu memahami

Bersama rasa ini

Aku tak akan mengingkari janji

Bersabarlah...

Kita akan terus bersama

Jangan ada kata lelah

Semua ini karena cinta

Setelah lagu di atas dinyanyikan kemudian dilanjutkan dengan memainkan pola dari tema besar yang telah dipaparkan sebelumnya. Lagu di atas merupakan lagu dengan bentuk satu bagian dan menggunakan buku yang ditulis oleh Karl 
Edmund Prier SJ (2015: 8) Ilmu Bentuk Musik, Yogyakarta: Pusat Musik Liturgi sebagai acuan terciptanya lagu tersebut. Pola dari tema besar karya ini dimainkan oleh instrumen gambus, flute, dan biola sebagai melodi pokok yang diterapkan dengan menggunakan teknik unisono dan improvisasi selain itu, melodi yang dimainkan pada bagian ini merupakan intro dari lagu pokok pada karya Siritano Sinda serta, lagu ini adalah representasi dari rasa sedih yang sangat dalam dirasakan oleh Lilimbuta dan Lilimbuto pada saat mereka berdua terpisahkan yang disebabkan jarak dan keyakinan masyarakat pada masa itu. Berikut merupakan bentuk lagu yang dimainkan.

Tangga nada Minor $\mathrm{La}=\mathrm{G}$

4/4

Moderato

$\|\ldots 3|6 \ldots| \ldots 7|5 \ldots| \ldots 3 \overline{23}|\ldots 6| 5 \ldots 6 \mid 3 \ldots\|$

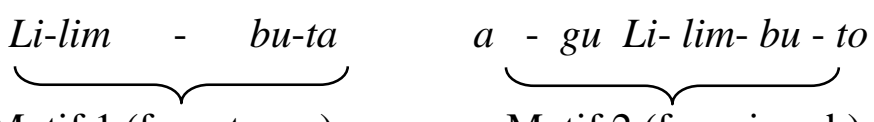

Motif 1 (frase tanya) Motif 2 (frase jawab)

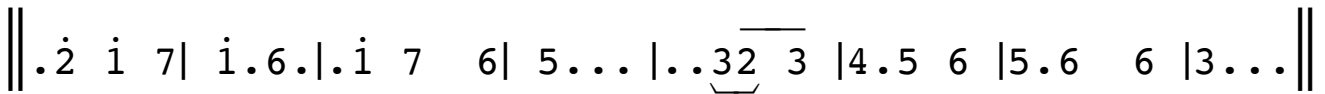

diper-te-mukan untuk cin-ta

Motif 1 (frase tanya) me-re-ka a-tas i-zin tu-han c. Akhir (pertemuan)

Secara keseluruhan musik yang dimainkan pada bagian ini merupakan representasi dari peristiwa dimana Lilimbuto bertemu dengan Lilimbuta yang secara tidak sengaja di sebuah tempat yang berdekatan dengan gunung Pogoguyo (Pogogul), dan juga representasi dari proses pelarian Lilimbuta dan Lilimbuto dari kelompok masyarakat yang tidak

Tangga nada Minor $\mathrm{La}=\mathrm{G}$ memperbolehkan mereka berdua menjalin cinta, hingga proses ikrar cinta sebagai ending dalam karya Siritano Sinda. Pola permainan yang disajikan pada bagian ini dimainkan dengan menggunakan vokal unisono sebagai pembuka selain itu, lagu yang terdapat pada bagian ini merupakan bentuk lagu satu bagian yang diulang sebanyak dua kali. Berikut merupakan bentuk lagunya. 
$4 / 4$

Moderato

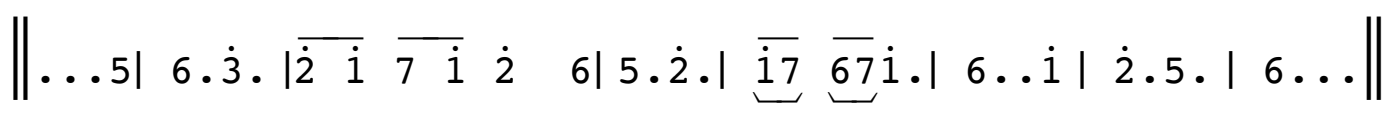

Ki-to se-bagai-manusia na-i me-ra-gu-kan ke-a-gungan-Nya

Lagu di atas merupakan representasi dari pertemuan Lilimbuta dan Lilimbuto secara kebetulan disebuah hutan yang berada dekat di gunung Pogoguyo. Lirik dalam lagu ini merupakan cerminan untuk peristiwa yang dialami oleh kedua insan tersebut, serta lagu ini memiliki makna yaitu kita sebagai umat manusia sesama ciptaan Tuhan yang maha Esa janganlah meragukan kebesaran-Nya, dan jika Tuhan menghendakinya maka terjadilah begitupun yang terjadi kepada kisah cinta Tilo Manurung. Makna tersebut terdapat pada Al-Qur'an surah Al-Baqarah ayat 117 dan dijadikan acuan pada proses penciptaan lagu di atas. Kemudian musik dilanjutkan dengan permainan tempo yang cepat sebagai representasi peristiwa Lilimbuta dan Lilimbuto yang melarikan diri dari kejaran sekelompok masyarakat yang ingin menangkap mereka berdua hingga ke sebuah gunung yang bernama Pogoguyo. Musik pada bagian ini dimainkan dengan menggunakan pola permainan dengan ketukan 7/4, menggunakan teknik unisono, filler, improvisasi dan membagi suara gambus satu dan gambus dua. Berikut adalah notasinya.

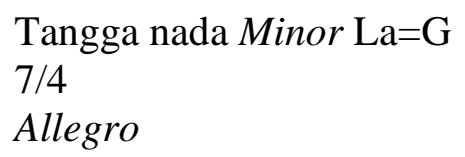

Unisono

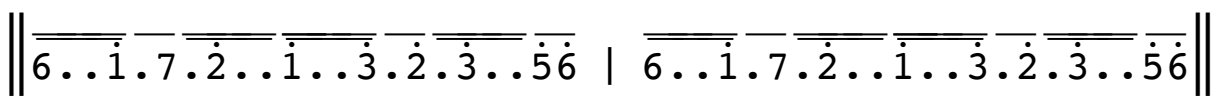

Gambus I

$\|\overline{6 \dot{3}} \overline{\dot{3} \dot{2}} \overline{\overline{4} \ldots \dot{3}} \overline{2} \dot{3} \cdot \dot{i} \dot{2} \overline{57} \mid \overline{6 \dot{3}} \overline{\dot{3} \dot{2}} \overline{\dot{4} \ldots \dot{3}} \overline{2} \dot{3} \cdot \bar{i} \dot{2} \overline{57}\|$

Gambus II

$\|\overline{36} \overline{657.66} \overline{\overline{56.4}} \overline{524} \mid \overline{36} \overline{657 \ldots 6} \overline{\overline{56}} \overline{\overline{7} .4} \overline{524}\|$

Kulintang

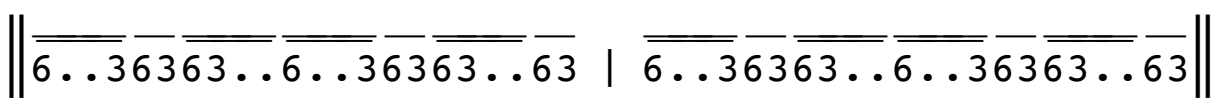

Xylophone 


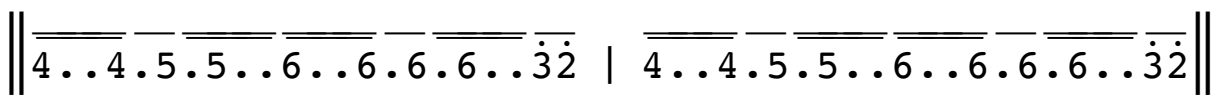

Hawaiian

$\|\dot{3} \cdot \overline{\dot{5}} \cdot \dot{2} \cdot \overline{\dot{4}} \cdot \dot{3} \mid \dot{3} \cdot \overline{\dot{5}} \cdot \dot{2} \cdot \overline{\dot{4}} \cdot \dot{3}\|$

Kecapi Sunda

$\|\overline{6 \dot{3}} \cdot \overline{\dot{2}} \dot{4} \overline{\dot{2} \dot{3}} \cdot \bar{i} \dot{2} \overline{57} \mid \overline{6 \dot{3}} \cdot \overline{2} \dot{4} \dot{2} \dot{2} \cdot \overline{\dot{1}} \dot{2} \overline{57}\|$

Sasando

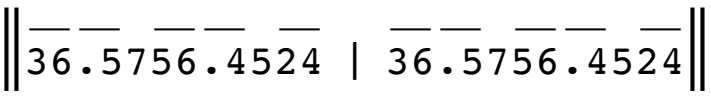

Biola dan Cello

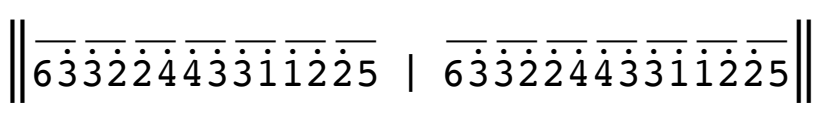

Musik pada bagian selanjutnya ini merupakan representasi dari peristiwa pada saat Lilimbuta dan Lilimbuto mengucapkan sumpah janji setia untuk seumur hidup mereka, dengan memohon restu kepada sang maha kuasa serta menjadikan alam menjadi saksi atas ikrar cinta mereka berdua. Adapun notasi yang dimainkan pada bagian akhir ini adalah sebagai berikut.

$$
\begin{aligned}
& \text { Rit... } \\
& \| \dot{3} \ldots \overline{\dot{4}} \mid \dot{3} \text { | } . \overline{\dot{3} \dot{2}}|\dot{i} \ldots \overline{\dot{2}}| 7 \dot{3} \dot{2} 5|6 . \dot{2} .| 7.65|6 \ldots| \ldots . . .
\end{aligned}
$$

Demikian notasi yang telah merupakan representasi saat Lilimbuto dipaparkan di atas merupakan akhir dari (perempuan) yang mencium tangan karya komposisi musik yang berjudul Lilimbuta (laki-laki) sebagai tanda mereka Siritano Sinda. Notasi di atas juga yang telah sah menjadi suami istri.

\section{Simpulan}

Siritano Sinda disajikan melalui komposisi musik etnis dengan menggunakan instrumen tradisi Buol yaitu gambus, kulintang dan rebana, yang dibalut dengan instrumen etnis Nusantara yaitu hawaiian, sasando, dan kecapi sunda, serta didukung

oleh instrumen barat sebagai sumber bunyi. Teknik permainan yang digunakan didominasi oleh gaya permainan Gambus Jepeng dan Tog Doka khas Buol, serta imbal dan dipadukan dengan teknik permainan dari musik barat sebagai 
Jurnal Etnomusikologi

representasi dari cerita masyarakat Buol

dalam komposisi musik etnis Siritano

Sinda.

\section{E. Daftar Pustaka}

Damono, Supardi Djoko. 2018. Alih Wahana. Jakarta : Gramedia Pustaka Utama.

Djohan. 2010. Respon Emosi Musikal. Bandung : Lubuk Agung.

Hawkins, Alma M. 1990. Mencipta Lewat Tari Bandung : Lubuk Agung.. Yogyakarta : Institut Seni Indonesia.

Mailili, Maryam G. 2009. Kamus Bahasa Daerah Buol, Makassar : PT. Umitoha Ukhuwah Grafika.

Prier, Karl Edmund SJ. 2015. Ilmu Bentuk Musik. Yogyakata : Pusat Musik Liturgi.

Prier, Karl Edmund SJ. 1996. Ilmu Bentuk Musik. Yogyakata : Pusat Musik Liturgi.

Samad, A. Rahma. Jilid I. Sejarah Buol. Sulawesi Tengah : tp, tt.

Saragih, Winnardo. 2008. Misi Musik. Yogyakarta : ANDI 